\title{
Estimation of male stature by ulnar length in Madhya Pradesh region by using linear regression analysis
}

\author{
Marskole S.K. ${ }^{1}$, Sharma D. ${ }^{2}$, Sharma V.A. ${ }^{3}$, Baweja S.S. ${ }^{4}$ \\ ${ }^{1}$ Dr. Sandeep K Marskole, Assistant Professor, ${ }^{2}$ Dr. Deepak Sharma, P.G. Student, ${ }^{3}$ Dr. Vandana A Sharma, Associate \\ Professor \& Head, ${ }^{4}$ Dr. Sonia S Baweja, Associate Professor, all authors are affiliated with Department of Anatomy, \\ Gandhi Medical College, Bhopal, MP, India.
}

Address for Correspondence: Dr. Sandeep K Marskole, Assistant Professor, Department of Anatomy, Gandhi Medical College, Bhopal. E - mail - sandeepanatomy@gmail.com

\begin{abstract}
Introduction: Establishment of reliable formula for stature estimation from fragments of bones especially in forensic examination is important for individual identification. Sexual differences in height and of long bones exist so there is need for studies emphasizing quantitative standards of sexual dimorphism in different populations. Limited availability of gender specific studies of stature estimation by using individual bones provide data for forensic identification that led me to study ulna bone to establish a linear regression equation for stature estimation in living adult males of age group 18-26 yrs in Madhya Pradesh region. Material \& Methods: Cross sectional study was conducted in Department of Anatomy, Gandhi Medical College, Bhopal (M.P.) on 238 males by using anthropometer and spreading caliper and statistically analyzed. Ulna length were measured independently on right and left sides of each subject with the help of spreading caliper from the tip of olecranon process to the tip of styloid process and vertex to heel height was measured in the standing erect posture with subject looking forward straight to the horizon. Results: Value of correlation coefficient(r) of right ulna with stature was found to be 0.995 and left ulna with stature was 0.997 . Regression equations and graphs interpret the height from the ulnar length in males. Conclusion: The regression formula derived will be useful for anatomists, clinician, anthropologists and forensic experts for estimation of the individual stature in Madhya Pradesh region for establishing identity.
\end{abstract}

Keywords: Male Stature, Olecranon, Ulnar length.

\section{Introduction}

Anthropometry is defined as systematized techniques for measuring and taking observations on man, his skeleton, the skull, the limbs, and trunk etc., as well as the organs, by the most reliable means and scientific methods. Anthropometric characteristics have a direct relationship with age, sex, shape, and form of an individual. These factors are intimately linked with each other and manifestation of the internal structure and tissue components which in turn are influenced by environmental and genetic factors [1]. As infants grow, they change their body proportions gradually towards adult shapes; these proportions diverge towards one sex at puberty. Assessment of stature from the different

Manuscript received: $6^{\text {th }}$ February 2017

Reviewed: $15^{\text {th }}$ February 2017

Author Corrected: $22^{\text {nd }}$ February 2017

Accepted for Publication: $28^{\text {th }}$ February 2017 parts of the body by the anthropometric study of the skeleton is an area of interest to anatomist, anthropologists and to forensic experts [2,3].

Estimation of stature from the measurement of limb bones has long been formulated and the accuracy of such estimations improved over time. Most forensic and anthropological studies use stature estimation developed by an eminent scientist [4]. Pearson K first introduced the correlational calculus into the field of work for prediction of stature from the measurement of long bones. Height is one of the factors in the description of impressiveness of an individual and it varies with race, age, sex, heredity, climate and nutritional status [5]. Telkka A. et al, worked on bones of Finns expressed the opinion that each racial group needs a separate formula 
for estimation of stature. He measured six long bones such as humerus, radius, ulna, femur, tibia and fibula to obtain stature of the corpse [6].

Establishment of reliable formula for stature estimation from fragments of bones is especially important for individual identification. Sexual differences in height and long bones exist, so there is a need for studies to emphasize the need for standards of sexual dimorphism in a different population. Lundy JK discussed the regression equation, mathematical and anatomical method for estimating living stature from long limb bones $[7,8]$. In ancient observation in India (Charaka and Vagbhat) that the height of an individual is nearly three and a half times the length of his "cubit" (point of the elbow to the tip of middle finger), hence the radius and ulna were considered the most suitable bones for deriving a relationship with height [9].
Cadavers cannot represent the population and might have suffered from the chronic debilitating disease, likely to have been lying in an abnormal posture and it may be not possible to straighten the body to get accurate stature measurement.

All these problems led me to study in the living males. In the present study, the ulna is selected to establish a relationship between stature of individual and length of ulna as a tool for forensic identification and anthropometric studies, because ulna is subcutaneous throughout its length.

Hence it is easily approachable for the measurement. The purpose of present study was to find out the height of all subjects by measuring maximum ulna length and correlation of height with the length of ulna by the regression equation.

\section{Material and Methods}

The present study was conducted in Department of Anatomy, Gandhi Medical College, Bhopal (M.P.) on a total 238 male subjects by using anthropometer and spreading caliper after due permissions and informed consent from the subjects. Subjects who have any kind of ailments or upper limb deformity and those who did not give consent for participation in the study were excluded.

Ulna length was measured independently on right and left sides of each subject with the help of spreading caliper from the tip of olecranon process to the tip of the styloid process with elbow flexed and palm spread over opposite shoulder[Figure-1]. Vertex to heel height was measured in the standing erect posture with the subject looking forward straight to the horizon so that Frankfurt's plane remains horizontal. Height was measured from floor level to the highest point over the head marked by the tangentially placed ruler [Figure-2]. All measurements were taken between 2:00 PM to 3:00 PM because of diurnal variation in height.

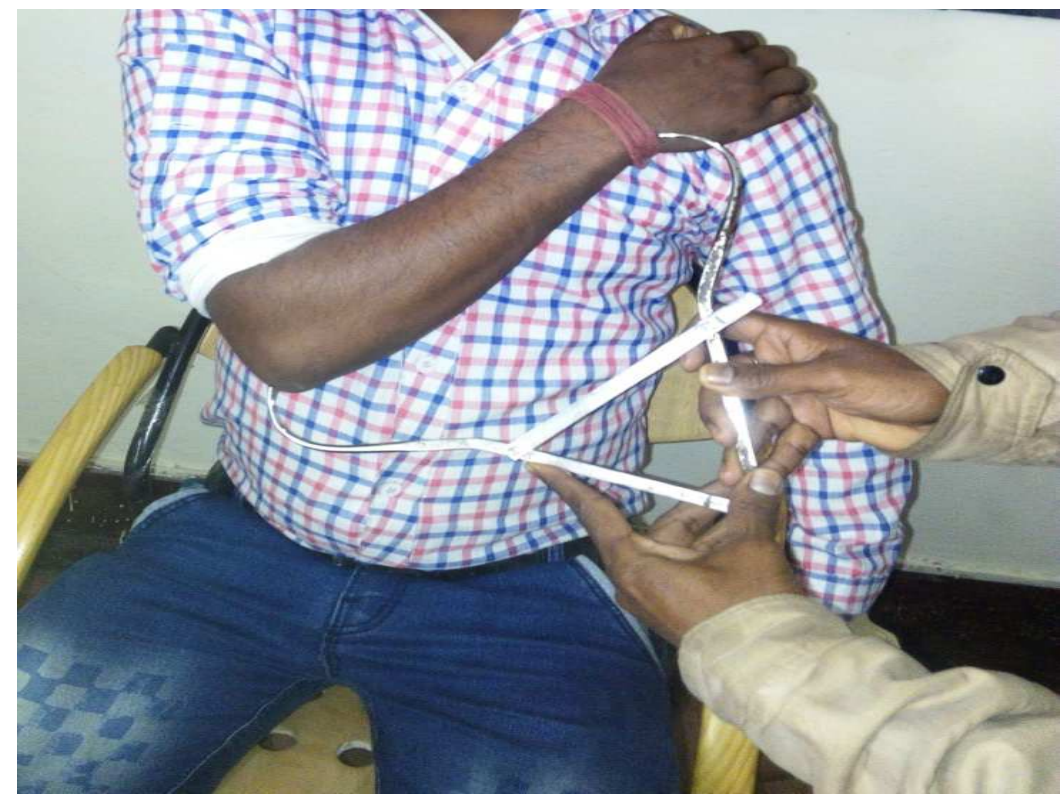

Figure-1: Showing ulna measurement 


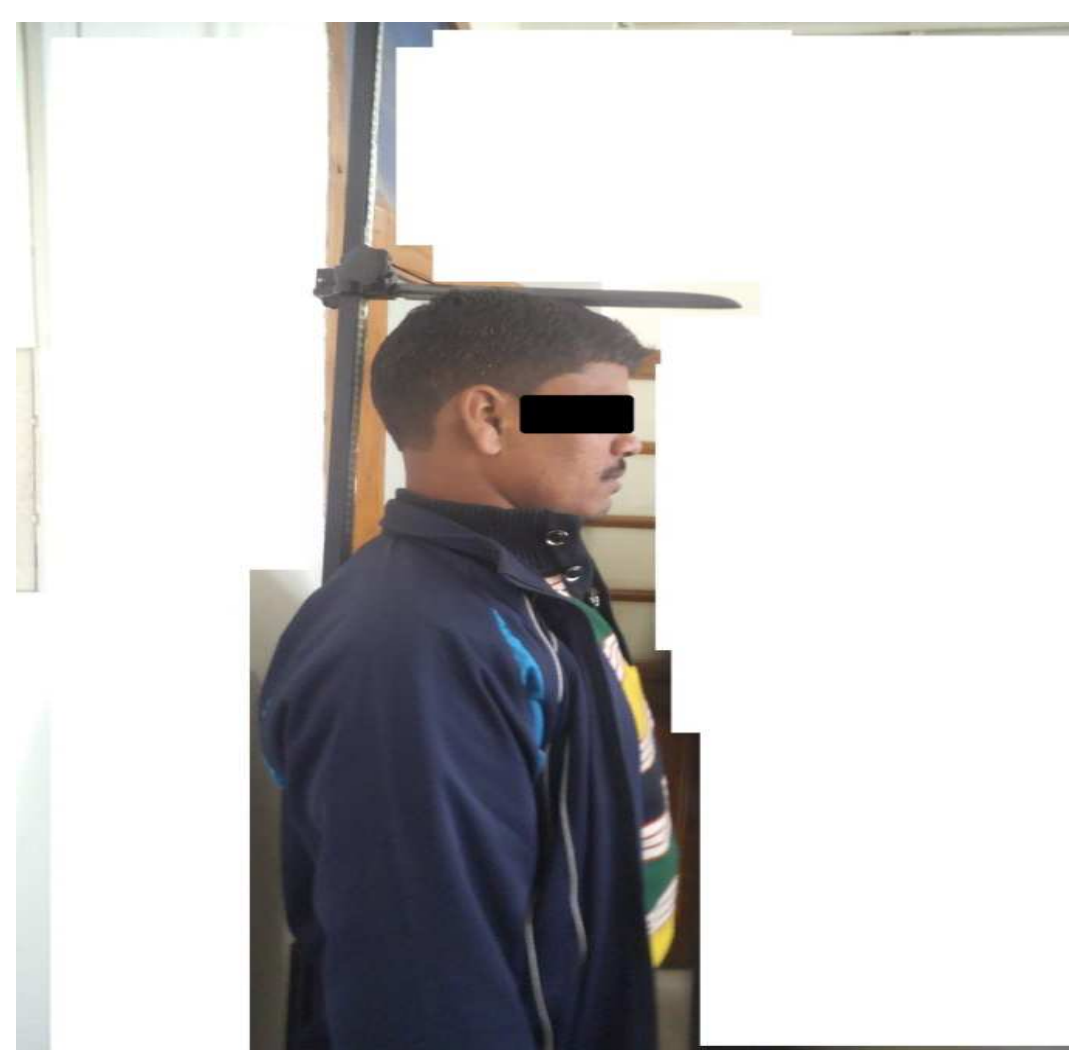

Figure-2: Showing Stature measurement

The correlation coefficient measures the relationship or association between two quantitatively measures or continuous variables. The extent or degree of relationship between two sets of figures is measured in terms of another parameter called correlation coefficient. It is denoted by letter ' $r$ '. It is calculated by following formula:-

$$
r=\frac{\sum(x-\bar{x})(y-\bar{y})}{\sqrt{\sum(x-\bar{x})^{2} \sum(y-\bar{y})^{2}}}
$$

Like correlation, regression is also used to describe the relationship between two variables. Linear regression helps in predicting the values of the dependent variable, given that we know the values of the independent variable. At least two observations on a data pair (i.e. variable $\mathrm{x}$ and $\mathrm{y}$ ), is needed to derive a linear equation.

The general form of the equation is $Y=a+b x$

The obtained values were used for the statistical analysis which was done by using the SPSS-14.0 software for the required analysis. As in our study, a 95\% confidence interval (which was equivalent to 1.96 standard deviations) was accepted and the standard error of regression (STE) was calculated. Therefore the final equation in our study is $\mathbf{Y}=(\mathbf{a}+$ bx) $\pm(\mathbf{1 . 9 6} \times \mathbf{S T E}) . \mathbf{Y}$ denotes height, $\mathbf{a}$ value of constant, $\mathbf{b}$ regression coefficient and $\mathbf{x}$ length of ulna.

\section{Results}

All the male subjects under study were in the range of 18- 26 yrs with the highest frequency in 21-22 yrs (31.9\%) of age group followed by 22-23 years $19.3 \%$ ) and 20-21 years (18.9\%) age group [Table-1]. Height of the subjects were range from $154.4 \mathrm{cms}$ to $188.4 \mathrm{cms}$. Mean stature height was $168.19 \mathrm{cms}$ [Table-2 \& 3]. In the present study, ulnar length was range from 24.5 to $32,9 \mathrm{cms}$, with mean ulnar length $27.77 \mathrm{cms}$ [Table-3]. The mean length of the right ulna was 27.88 cms and left ulna was $27.67 \mathrm{cms}$ [Table-2]. 
Table 1: Age distribution of all subjects.

\begin{tabular}{|c|c|}
\hline Age group (in years) & Total numbers and percentage (\%) \\
\hline $18-19$ & $07(0.08 \%)$ \\
\hline $19-20$ & $22(9.24 \%)$ \\
\hline $20-21$ & $45(18.9 \%)$ \\
\hline $21-22$ & $76(31.9 \%)$ \\
\hline $22-23$ & $46(19.3 \%)$ \\
\hline $23-24$ & $28(11.7 \%)$ \\
\hline $24-25$ & $05(2.1 \%)$ \\
\hline $25-26$ & $09(3.8 \%)$ \\
\hline Total & $\mathbf{2 3 8}$ \\
\hline
\end{tabular}

Table 2: Mean and standard deviation of stature and length of ulna of all subjects

\begin{tabular}{|c|c|c|c|}
\hline Age in years & $\begin{array}{c}\text { Height } \\
\text { mean } \pm \text { SD }\end{array}$ & length of Rt. ulna mean \pm SD & $\begin{array}{c}\text { length of Lt. } \\
\text { ulna mean } \pm \text { SD }\end{array}$ \\
\hline $18-26$ & $168.19 \pm 5.62$ & $27.88 \pm 1.55$ & $27.67 \pm 1.53$ \\
\hline
\end{tabular}

Table 3: Selected parameters for all subjects.

\begin{tabular}{|c|c|}
\hline Parameter & Values and Ranges \\
\hline$\bullet$ Total No. of subjects & 238 \\
\hline$\bullet$ Mean age & $154.18 \pm 1.50$ \\
\hline$\bullet$ Height Range (cm) & $168.19 \pm 5.62$ \\
\hline$\bullet$ Mean Height & $24.50-32.90$ \\
\hline$\bullet$ Ulna length Range (cm) & $27.77 \pm 1.25$ \\
\hline$\bullet$ Mean ulna length & 0.995 (Height - Right Ulna) \\
\hline$\bullet$ Correlation coefficient & 0.997 (Height - Left Ulna) \\
\hline$\bullet$ Regression coefficient (b) & $3.60 \& 3.64$ (Right \& Left Ulna) \\
\hline$\bullet$ Value of constant ( a) & $67.60 \& 67.30$ (Right \& Left Ulna) \\
\hline
\end{tabular}

Table 4: Correlation coefficient between height and ulna length.

\begin{tabular}{|c|c|c|c|}
\hline Parameter & Coefficient Value & Probability & Result \\
\hline Height - Right Ulna & .995 & $<0.01$ & Significant \\
\hline Height - Left Ulna & .997 & $<0.01$ & Significant \\
\hline
\end{tabular}

In this study, stature height of the males were significantly correlated with the right ulnar length $(r=0.995, p<0.01)$ and left ulnar length $(r=0.997, p<0.01)$ [Table-4]. The regression equation for stature estimation in the present study was derived by formula $\mathbf{Y}=(\mathbf{a}+\mathbf{b x}) \pm(1.96 \times$ standard error of regression $)$. For height, $Y=67.60+3.60($ Right ulna length) $\pm(1.078)$ and $67.30+3.64($ Left ulna length $) \pm(0.784)$. 


\section{Discussion}

The stature of an individual is an inherent characteristic. The estimation of which is considered to be an important assessment in the identification of unknown human remains. Height-estimation formulae based on length of ulna show similar levels of accuracy to calculations based on the length of other long bones of upper limbs [4]. Various methodologies have been proposed to estimate the stature from long bones of limbs, but regression analysis proved to be the easiest and the reliable method $[2,10,11]$.

Ilayperuma I et.al conducted a study, in the age group of 20-23 years on medical students for estimation of stature from the length of forearm [2]. Similar to above studies, in our study, age group of 18 to 26 years is selected because up to the age of $18^{\text {th }}$ years in male ossification of ulna bone is completed [3].

Thummar B et al, conducted a study in the age group of 20-40 years, for estimation of height from the ulnar length in Gujrat, and found mean height of the male was $169.87 \mathrm{~cm}$, whereas mean right ulnar and left ulnar length in male were $28.48 \mathrm{~cm}$ and $28.39 \mathrm{~cm}$ respectively [10]. Mondal MK et al, reported that mean height of the male was $164.32 \mathrm{~cm}$, whereas mean right ulnar length and left ulnar length were $27.13 \mathrm{~cm}$ and $27.01 \mathrm{~cm}$ respectively [12]. Similar to above studies, in the present study, the mean height of subjects was $168.19 \mathrm{~cm}$ and mean length of the right ulna and left ulna was $27.88 \mathrm{~cm}$ and $27.67 \mathrm{~cm}$ respectively.

Various studies had shown significant correlation between height and ulna bone length, other long bones and different parts of the body [13-15]. In our study there is linear relationship showing positive correlation between height and length of the ulna[Graph 1\&2].

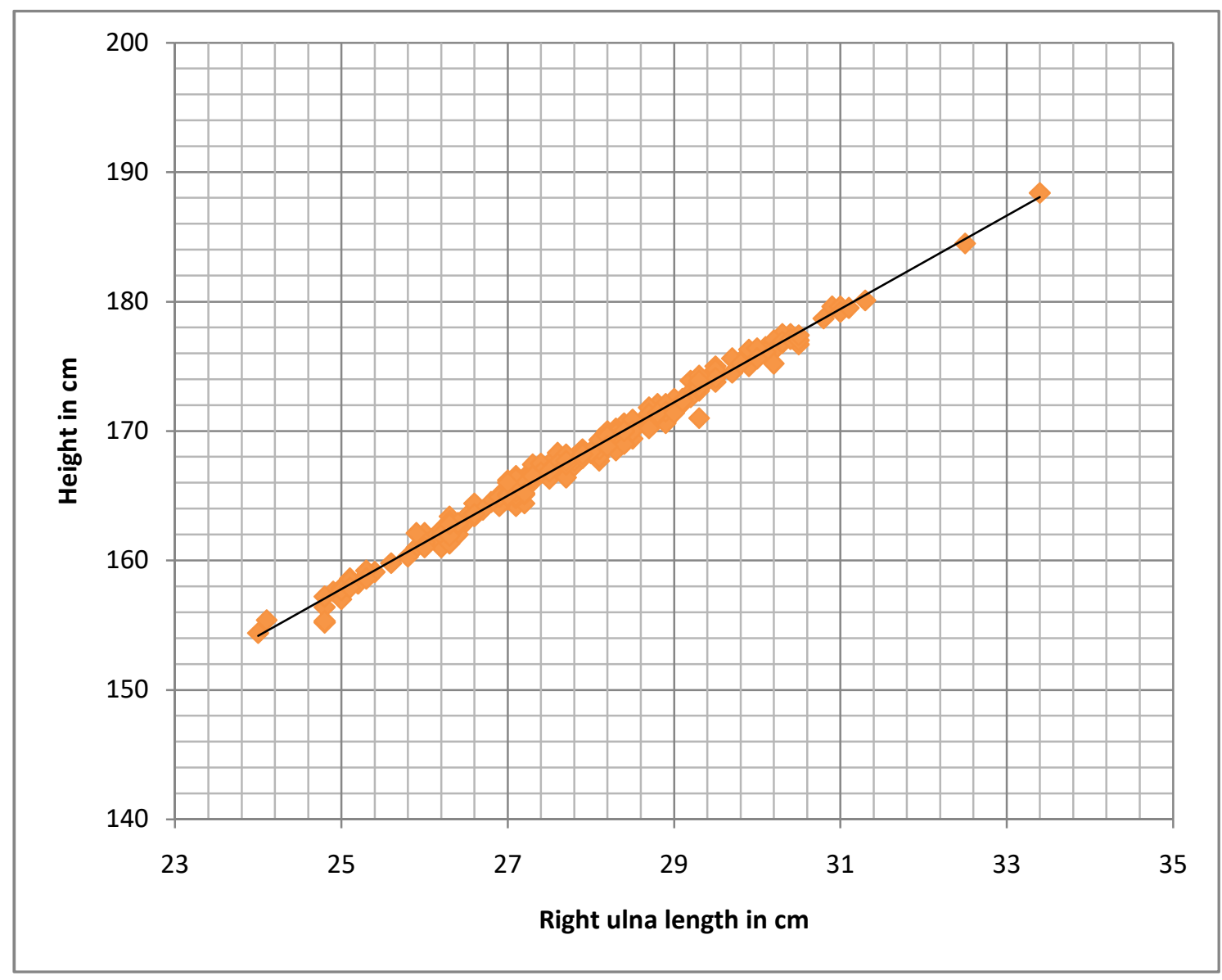

Graph-1: Linear regression line showing positive relationship between stature and right ulna length of all subjects 


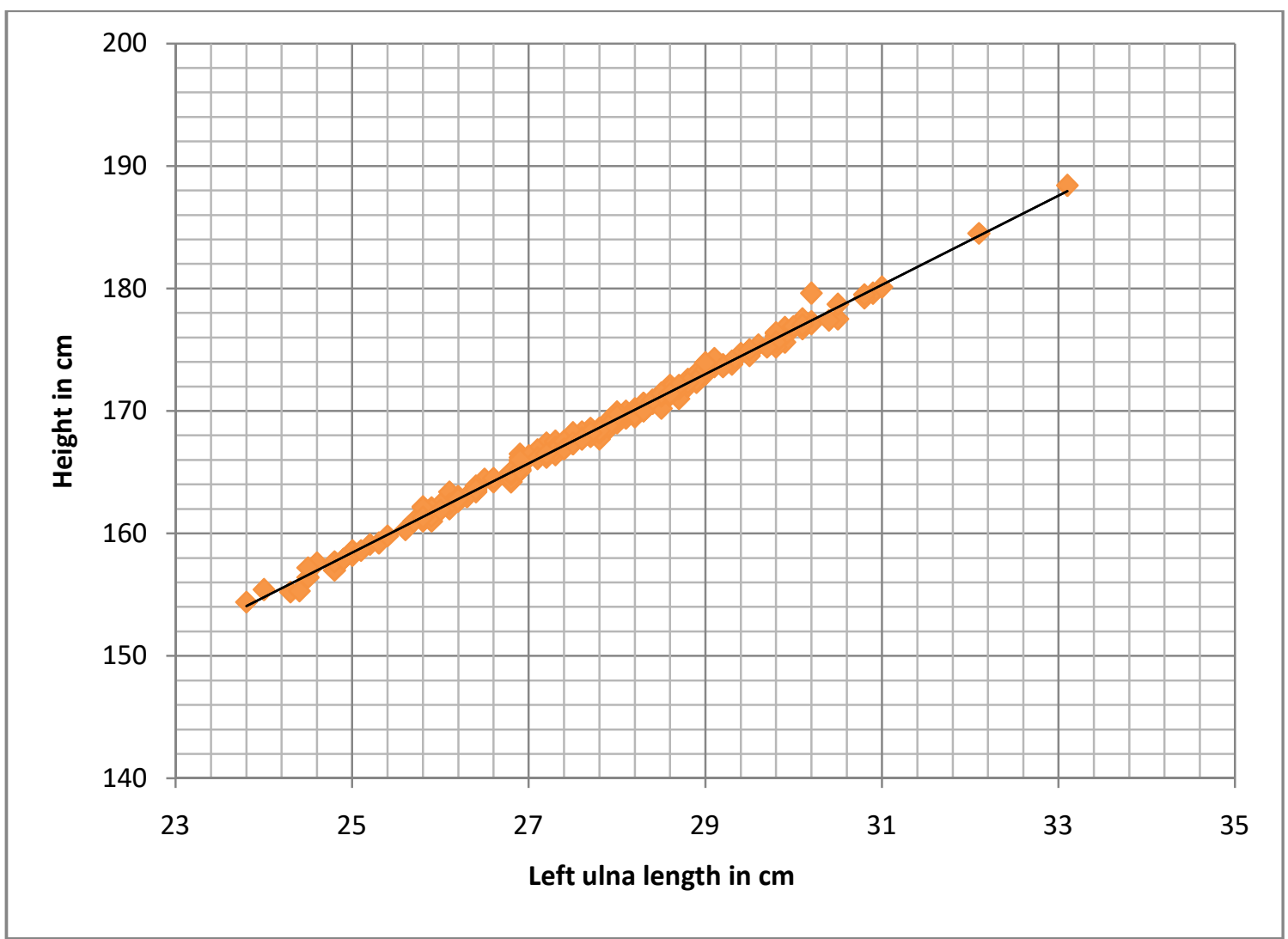

Graph-2: Linear regression line showing positive relationship between stature and left ulna length of all subjects

Trotter $\mathrm{M}$ et al, reported that different regression equations were required among different races, for establish the relationship between lengths of the long bones and stature. It is important to note that every race of particular age group and sex should have its own equations for estimation of height using various parameters [4].

In the present study, two separate formulae were derived for males of age group 18 to 26 years for estimation of stature from the measurement of ulna length in Madhya Pradesh region.

a. Estimation of height from right ulna: $Y_{1}=67.60+3.60$ (Rt. ulna length) $\pm(1.078)$

b. Estimation of height from left ulna: $Y_{2}=67.30+3.64$ (Lt. ulna length) $\pm(0.784)$

\section{Conclusion}

The correlation coefficient between the total height of male and their ulna length was found to be statistically significant. Regression models for stature prediction were formulated using lengths of the ulna and checked for their accuracy by comparing the estimated stature and the actual stature. Our results further confirmed that ulna length provides an accurate and reliable means in stature prediction. The regression models proposed will be of immense practical use in clinical practice, medicolegal and anthropometric studies where total height of a subject can be calculated if the ulna length is known.

Funding: Nil, Conflict of interest: None.

Permission of IRB: Yes

\section{References}

1. Krishnan K. Anthropometry in Forensic medicine and forensic science. 'Forensic Anthropometry'. The internet journal of forensic science. 2007; 2 (1): $1-8$.

2. Ilayperuma,I; A for the estimation of personal stature from the length of forearm. International journal Morphology, 28 [4];1081-1086, 2010.

3. Soames R.W., Bannister LH, Berry MM, Collins P. et al. Gray's Anatomy Anatomical basis of Medicine and Surgery, 38 th edition; Churchill Livingstone, London, 1999; pp433-434, 637-640. 
4. Trotter M, Gleser GC. A re-evaluation of estimation of stature based on measurements of stature taken during life and of long bones after death. Am J Phys Anthropol. 1958 Mar;16(1):79-123.

5. Pearson K, Bell J.A study of the long bones of the English skeleton. $1^{\text {st }}$ ed. Cambridge University Press, 1917.

6. Telkka A. On the prediction of human stature from the long bones. Acta Anat (Basel). 1950;9(1-2):103-17.

7. Lundy JK. Regression Equations for Estimating Living Stature from Long Limb Bones in the SouthAfrican Negro. South African Journal of Science. 1983 Jan 1;79(6):337-8.

8. Lundy JK. The mathematical versus anatomical methods of stature estimate from long bones. Am J Forensic Med Pathol. 1985 Mar;6(1):73-6.

9. Athawale MC. Estimation of height from lengths of forearm bones. A study of one hundred maharashtrian male adults of ages between twenty-five and thirty years. Am J Phys Anthropol. 1963 Jun;21:105-12.
10. Thummar B, Patel ZK, Patel S, Rathod SP. Measurement of Ulnar Length for estimation of Stature in Gujarat. National Journal of Integrated Research in Medicine.2011;1(2):36-40.

11. Meadows L, Jantz RL. Allometric secular change in the long bones from the 1800 s to the present. J Forensic Sci. 1995 Sep;40(5):762-7.

12. Mondal MK, Jana TK, Das J, Biswas S. Use of length of ulna for estimation of stature in living adult male in Burdwan district and adjacent areas of West Bengal. J Anat Soc India. 2009 Jun 1;58:16-8.

13. ALLBROOK D. The estimation of stature in British and East African males. Based on tibial and ulnar bone lengths. J Forensic Med. 1961 Jan-Mar;8:15-28.

14. Saxena SK, Jeyasingh P, Gupta AK, Gupta CD. The estimation of stature from head-length. Journal of anatomical society of India. 1981; 30:78-9.

15. Devi S, Das H, Purnabati BK, Singh SD, Devi J. Estimation of stature from the upper arm length among the Marings of Manipur. Ind Med J. 2006 Aug; 100(8):271-73.

\section{How to cite this article?}

Marskole S.K, Sharma D, Sharma V.A, Baweja S.S. Estimation of male stature by ulnar length in Madhya Pradesh region by using linear regression analysis. Int J Med Res Rev 2017;5(02):137-143. doi:10.17511/ijmrr. 2017.i02.07. 